\title{
Induction of Brain Region-Specific Forms of Obesity by Agouti
}

\author{
Martien J. H. Kas, ${ }^{1}$ Birgitte Tiesjema, ${ }^{1}$ Gertjan van Dijk, ${ }^{2}$ Keith M. Garner, ${ }^{1}$ Gregory S. Barsh, ${ }^{3}$ Olivier Ter Brake, ${ }^{4}$ \\ Joost Verhaagen, ${ }^{4}$ and Roger A. H. Adan ${ }^{1}$ \\ ${ }^{1}$ Rudolf Magnus Institute of Neuroscience, Department of Pharmacology and Anatomy, University Medical Centre Utrecht, 3584 CG Utrecht, The \\ Netherlands, ${ }^{2}$ Division of Neuroendocrinology, Department of Animal Physiology, University of Groningen, 9750 AA Haren, The Netherlands, ${ }^{3}$ Department \\ of Pediatrics and Genetics, Howard Hughes Medical Institute, Stanford University, Stanford, California 94305, and ${ }^{4}$ Graduate School Neurosciences \\ Amsterdam, Netherlands Institute for Brain Research, 1105 AZ Amsterdam, The Netherlands
}

Disruption of melanocortin (MC) signaling, such as by ectopic Agouti overexpression, leads to an obesity syndrome with hyperphagia, obesity, and accelerated body weight gain during high-fat diet. To investigate where in the brain disruption of MC signaling results in obesity, long-term Agouti expression was induced after local injections of recombinant adeno-associated viral particles in selected brain nuclei of adult rats. Agouti expression in the paraventricular nucleus, a hypothalamic region with a high density of MC receptors, induced acute onset hyperphagia and rapid weight gain that persisted for at least 6 weeks. In contrast, obesity and hyperphagia developed with a 3 week delay when Agouti was expressed in the dorsal medial hypothalamus. Agouti expression in the lateral hypothalamus (LH) did not affect food intake and body weight during regular diet, despite the presence of $\mathrm{MC}$ receptors in this region. However, during exposure to a high-fat diet, animals with Agouti expression in the LH exhibited a marked increase in body weight. Here we show that the LH is important for the protection against diet-induced obesity by controlling caloric intake during consumption of a high-fat diet. Together, this study provides evidence that different aspects of the Agouti-induced obesity syndrome, such as hyperphagia and diet responsiveness, are mediated by distinct brain regions and opens challenging opportunities for further understanding of pathophysiological processes in the development of the obesity syndrome.

Key words: melanocortin; obesity; lateral hypothalamus; dorsal medial hypothalamus; paraventricular nucleus; high-fat diet

\section{Introduction}

Genetic studies have shown that the yellow coat color and the obesity syndrome in rodents with ectopic Agouti overexpression are regulated independently by Agouti antagonism of the melanocyte-stimulating hormone receptor-1 (MC1-R) and of the MC4-R, respectively (Duhl et al., 1994; Lu et al., 1994; Fan et al., 1997; Huszar et al., 1997). Although Agouti antagonism of the MC1-R in the skin causes a yellow fur by switching eumelanin into phaeomelanin pigment synthesis (Ollmann et al., 1998), it is not fully understood where and how Agouti expression generates the obesity syndrome. Because pharmacological blockade or genetic disruption of the MC4-R lead to hyperphagia and obesity (Huszar et al., 1997; Kim et al., 2000; Adage et al., 2001) and the MC4-R is expressed in distinct brain areas (Gantz et al., 1993; Mountjoy et al., 1994; Kishi et al., 2003), it is hypothesized that central Agouti expression accounts for hyperphagia and subsequent body weight gain within the yellow obese syndrome.

Although the melanocortin signaling pathway is clearly involved in body weight control by affecting food intake (Fan et al.,

Received June 29, 2004; revised Sept. 28, 2004; accepted Sept. 28, 2004.

This research was supported by Dutch Foundation for Scientific Research Project ZonMW 903-039-193.

Correspondence should be addressed to either Roger A. H. Adan or Martien J. H. Kas, Universiteitsweg 100, 3584

CG Utrecht, The Netherlands. E-mail: r.a.h.adan@med.uu.nl or m.j.h.kas@med.uu.nl.

DOI:10.1523/JNEUROSCI.3442-04.2004

Copyright $\odot 2004$ Society for Neuroscience $\quad 0270-6474 / 04 / 2410176-06 \$ 15.00 / 0$
1997; Huszar et al., 1997) and diet responsiveness (Butler et al., 2001), it is poorly understood whether one or different brain sites mediate those MC effects. Other investigators have used intranuclear injection of melanocortin ligands to study these questions (Kim et al., 2000; Wirth et al., 2001); however, this approach is limited by the relatively short time of action of these compounds in tissues, which does not allow measurement of obesity development over weeks or months. To study the relationship between MC pathway involvement in the obesity syndrome and the functional anatomy of the MC system, we locally interfered with melanocortin receptor signaling using vector directed gene expression technology.

The paraventricular nucleus of the hypothalamus (PVN) contains a high density of MC4-Rs that have been proposed to mediate $\mathrm{MC}$-induced changes in food intake. For example, single injections of MC4-R ligands in the PVN alter food intake and body weight in rodents (Kim et al., 2000; Wirth et al., 2001). Recent studies suggest that the dorsal medial hypothalamus $(\mathrm{DMH})$ is also involved in the regulation of hyperphagia (Chen et al., 2004). In addition, based on the outcome of classical lesion, electric stimulation, and electrophysiological studies, the lateral hypothalamus $(\mathrm{LH})$ has long been implicated in the regulation of energy metabolism (Anand and Brobeck, 1951; Delgado and Anand, 1953; Katafuchi et al., 1985). This idea is corroborated by the recent identification of LH neurons that express neuropep- 
tides involved in eating behavior, such as hypocretins/orexins and the melanin-concentrating hormone (MCH) (Zamir et al., 1986; de Lecea et al., 1998; Sakurai et al., 1998). PVN, DMH, and LH neurons express moderate to high levels of MC4-R (Gantz et al., 1993; Mountjoy et al., 1994; Kishi et al., 2003). As a first step toward understanding where in the brain disruption of MC signaling results in obesity, rats with $\mathrm{PVN}, \mathrm{DMH}$, or LH injections of either recombinant adeno-associated virus (rAAV)-Agouti or rAAV-enhanced green fluorescent protein (EGFP) were monitored when exposed to a regular or a high-fat diet.

\section{Materials and Methods}

Recombinant adeno-associated viral vector production. Construction of pTR-cytomegalovirus (CMV)-EGFP has been described previously (Eaton et al., 2002). Agouti was PCR amplified using as template a plasmid containing the mouse Agouti cDNA (paE65; a kind gift from Roger D. Cone, Oregon Health and Science University, Portland, OR) using oligos 5'aagcttgagatctgccgcaccatggatgtcacccg and 5'gaagaagctagctcagcagttggggttg. A (BglII and NheI digested) fragment containing the Agouti cDNA was cloned into BamHI and SpeI digested pTR-CMV-EGFP (this removes the EGFP cDNA; correct sequence of Agouti was confirmed by sequence analysis), which generated pTR-CMV-Agouti. Next, rAAV was generated via a two-component, adenovirus-free packaging system using the helper plasmid pDG [kindly provided by J. Kleinschmidt, Deutsches Krebsforschungszentrum, Heidelberg, Germany (Grimm et al., 1998)].

Recombinant AAV particles were produced by the method described previously by Hermens et al. (1999). Briefly, the vector plasmid pTRCMV-Agouti or pTR-CMV-EGFP and the helper plasmid pDG were cotransfected into human embryonic kidney (HEK) 293T cells using calcium phosphate precipitation (molar plasmid ratio, 1:1). The medium was replaced after $6 \mathrm{hr}$ by fresh DMEM containing $10 \%$ FCS, and the cells were incubated for $48 \mathrm{hr}$ at $37^{\circ} \mathrm{C}$ and $5 \% \mathrm{CO}_{2}$. Next, the cells were dislodged, harvested, and freeze-thawed three times to release the AAVparticles from the cells. Cell debris was removed using low-speed centrifugation. The supernatant was loaded on a Matrex Cellufine sulfate bead column (Amicon, Danvers, MA). After several washings with PBS, the virus was eluted from the column with PBS containing $1 \mathrm{~m} \mathrm{NaCl}$. Next, viral particles were banded on an iodixanol (Nycomed Pharm, Oslo, Norway) density gradient using ultracentrifugation, and fractions of $\sim 300 \mu \mathrm{l}$ were collected from the bottom of the gradient. To reduce viscosity of the iodixanol, rAAV-fractions were diluted 10 times with PBS and reconcentrated on a Centricon-100 concentrator (Amicon). The rAAV stocks contained $2 \times 10^{12}$ particles/ml for rAAV-Agoutiwoodchuck posttranslational regulatory element (WPRE) and $2 \times 10^{11}$ particles/ml for rAAV-EGFP-WPRE.

In vitro infection, Western blot analysis, and MC receptor activation assay. HEK 293 cells were infected (multiplicity of infection, 10) with rAAV-Agouti or rAAV-EGFP. Four days after infection, supernatant was collected. Aliquots $(20 \mu \mathrm{l})$ of the supernatant were diluted 1:1 with tricine sample buffer and separated on a $12 \%$ Tris/tricine gel. After electrophoresis, proteins were transferred to a nitrocellulose membrane and blocked by incubation for $1 \mathrm{hr}$ at room temperature with $10 \%$ nonfat milk in Tris-buffered saline/0.1\% Tween 20 (TBST). The membrane was incubated overnight with rabbit anti-Agouti antibody as the primary antibody (1:5000 dilution), followed by goat anti-rabbit peroxidase (1: 10,000 dilution) (Jackson ImmunoResearch West Grove, PA) for $60 \mathrm{~min}$ after washing with TBST. After washing with TBST, HRP-labeled antibodies were detected by chemiluminescence. Agouti- or EGFP-expressing HEK 293 cells were mixed at a 1:1 ratio with HEK 293 cells cotransfected with $100 \mathrm{ng}$ of an MC4 receptor expression vector (Oosterom et al., 1999) and $7 \mu \mathrm{g}$ of Cre-lacZ (Chen et al., 1995). Two days after transfection, melanocortininduced (0.01-100 nм MT-II) $\beta$-galactosidase activity was quantified using a colorimetric assay (Chen et al., 1995). $\mathrm{EC}_{50}$ values of MC-induced $\beta$-galactosidase activity in the presence of Agouti- or EGFP-producing cells were determined by fitting the data to a sigmoidal curve with variable slope using GraphPad Prism 2.01 for Windows 95/NT (GraphPad Software, San Diego, CA).

Animals. Male outbred rats [strain Wistar (U:WU)] (body weights between 240 and $260 \mathrm{gm}$ ) were maintained in a $12 \mathrm{hr}$ light/dark cycle (ambient temperature was $21.0 \pm 1.0^{\circ} \mathrm{C}$ ). Food (complete laboratory chow; Hope Farms, Woerden, The Netherlands) and water were available ad libitum. After $10 \mathrm{~d}$ of baseline recordings (body weight and food intake), rats were anesthetized with Hypnorm $(0.1 \mathrm{ml} / 100 \mathrm{gm}$ body weight, i.p.; Janssen Pharmaceutica, Beersse, Belgium) and Dormicum $(0.05 \mathrm{ml} / 100$ gm body weight, i.m., Hoffman-LaRoche, Mijdrecht, The Netherlands). Stereotaxic bilateral injections of rAAV-Agouti and rAAVEGFP (as a control) were performed in the PVN [ $-1.8 \mathrm{~mm}$ anteroposterior (AP), $0.3 \mathrm{~mm}$ mediolateral $(\mathrm{ML})$, and $-8.6 \mathrm{~mm}$ dorsoventral (DV), using bregma as a reference for AP and ML coordinates and the skull as a reference for DV coordinates], DMH $(-2.5 \mathrm{~mm} \mathrm{AP}, 0.3 \mathrm{~mm}$ $\mathrm{ML}$, and $8.4 \mathrm{~mm} \mathrm{DV}), \mathrm{LH}(-2.56 \mathrm{~mm} \mathrm{AP}, 1.55 \mathrm{~mm} \mathrm{ML}$, and $9.32 \mathrm{~mm}$ $\mathrm{DV})$, and $0.76 \mathrm{~mm}$ anterior of the PVN region $(-1.04 \mathrm{~mm} \mathrm{AP,} 0.3$ and $-0.3 \mathrm{~mm} \mathrm{ML}$, and $-8.6 \mathrm{~mm} \mathrm{DV})$. During $5 \mathrm{~min}, 1 \mu \mathrm{l}$ of virus $\left(2 \times 10^{8}\right.$ particles) was injected per site. After each injection, the needle remained stationary for an additional $5 \mathrm{~min}$ and was then removed.

After surgery, food intake and body weight were monitored at least every third day for no less than $42 \mathrm{~d}$. Animals were then provided with a high-energy diet (HED) with a high-fat content for 10 consecutive days (energy content of diets, $3731.9 \mathrm{kcal} / \mathrm{kg}$ in regular chow and $4655 \mathrm{kcal} / \mathrm{kg}$ in the HED; percentage energy derived from carbohydrate/protein/fat in diets, 63/23/14 in regular chow and 19/19/62 in the HED). After these $10 \mathrm{~d}$, all animals were anesthetized with sodium pentobarbital and perfused with saline, followed by perfusion with $4 \%$ paraformaldehyde (PFA). Brains were postfixed overnight with $4 \%$ PFA and cryoprotected in a $25 \%$ sucrose solution (overnight). Brains were than frozen in cold isopentane $\left(-30^{\circ} \mathrm{C}\right.$ for $\left.20 \mathrm{sec}\right)$. Cryostat sections $(20 \mu \mathrm{m})$ were used for Agouti immunohistochemistry and for in situ hybridization.

Agouti antibody staining. After pretreatment with $4 \%$ fetal calf serum and $0.3 \% \mathrm{H}_{2} \mathrm{O}_{2}$ in PBS, sections were incubated with a rabbit anti-Agouti antibody $\left(1: 5000\right.$, overnight at $\left.4^{\circ} \mathrm{C}\right)$. After a $1 \mathrm{hr}$ incubation with a secondary goat anti-rabbit-biotinylated antibody (1:100) (Jackson ImmunoResearch), sections were incubated with $\mathrm{ABC}$ (1:500) (Vector Laboratories, Burlingame, CA) for $1 \mathrm{hr}$ at room temperature. Sections were then treated with diaminobenzidine (1:100) (Sigma, St. Louis, MO) in PBS with $30 \% \mathrm{H}_{2} \mathrm{O}_{2}$ in PBS for $10 \mathrm{~min}$. All immunohistochemistry steps described above were followed by a three times rinse with PBS of at least 5 min per rinse. Slides were dehydrated in serial ethanol solutions, cleared with xylene, and coverslipped. For histological confirmation of the injection site, Agouti immunoreactivity in the injection sites was confirmed in every other section throughout the hypothalamus for all animals.

In situ hybridization. Pretreated $20 \mu \mathrm{m}$ cryostat sections from rat hypothalamus were hybridized with ${ }^{35} \mathrm{~S}$-labeled antisense mRNA probes for Agouti-related protein (AgRP), NPY, MCH, and orexins according to van der Kraan et al. (1998). mRNA expression in the arcuate nucleus (for $\mathrm{NPY}$ and AgRP) and lateral hypothalamus (for MCH and hypocretins/ orexins) was quantified using MCID-M5 (Imaging Research, St. Catharines, Ontario, Canada). mRNA levels are expressed in counts per minute as calculated from a standard curve of diluted probe mix on the same film on which the slides were measured. From each animal, two measurements per probe were taken in the region of interest (arcuate nucleus and lateral hypothalamus) and subsequently averaged to calculate the mean counts per minute per probe for that region.

Statistics. All data are expressed as mean \pm SEM. Differences in food intake, body weight, and mRNA expression levels were assessed using one-way and repeated-measure ANOVA, unless indicated differently in the text. In the presence of a significant main effect, the analysis was followed by Tukey's (SPSS for Windows, version 9.0; SPSS, Chicago, IL) contrasts $(\alpha=0.05)$.

Ethical commission. Animal research and care was approved by the Ethical Commission on Laboratory Animal Experiments of the School of Medicine, University of Utrecht (Utrecht, The Netherlands).

\section{Results}

An rAAV-Agouti vector under the control of a CMV promotor was generated and tested for efficacy to release the Agouti protein after infection. In contrast to the media of HEK 293 cells infected 
with the rAAV-EGFP control particles, substantial Agouti protein was demonstrated in the media of cells infected with the rAAV-Agouti particles by Western blot analysis (Fig. 1A). Thus, Agouti was produced and released from cells infected with rAAV-Agouti viral particles. Injection of $1 \mu \mathrm{l}$ of the rAAV-Agouti particles $\left(2 \times 10^{8}\right.$ particles $)$ in selected brain regions resulted in local Agouti expression (Fig. $1 B, C$ ). It was confirmed that Agouti protein was expressed for at least $60 \mathrm{~d}$ with an expression onset as early as $3 \mathrm{~d}$ after injection. No Agouti staining in target sites of these neurons, such as the brainstem, was observed. To demonstrate efficacy of Agouti to antagonize MC-induced receptor activation, HEK 293 cells expressing either EGFP or Agouti were mixed with cells transfected with human $\mathrm{MC}-4$ receptor and with Cre-lacZ (as a reporter for receptor stimulation), mimicking rAAV-Agouti infection in vivo with cells releasing Agouti in the surrounding of cells that express MC-4 receptors. The $\mathrm{EC}_{50}$ value of $\mathrm{MC}$-induced $\mathrm{MC}-4$ receptor stimulated Cre-lacZ in HEK 293 cells was right-shifted from 0.25 to $1.1 \mathrm{nM}$. This indicates that the released Agouti protein functionally antagonizes MC-4 receptor signaling.

Expression of the MC4-R antagonist Agouti in the PVN of adult rats increased body weight and food intake within $7 \mathrm{~d}$ after the injection of rAAV-Agouti compared with injection of rAAVEGFP (Fig. 2A,B). These elevated levels of food intake and body weight gain remained for over 6 weeks. In this episode, PVNinjected rats ate on average $4 \mathrm{gm} / \mathrm{d}$ more than controls, resulting in a $50 \%$ increase in body weight gain $(p=0.0001)$. Histological confirmation of Agouti expression indicated that injections leading to Agouti expression just outside of the PVN region (missed; $n=5$ ) were insufficient to induce the rapid onset hyperphagia, in contrast to animals with confirmed PVN Agouti expression $(n=$ 7) [average food intake for the last $3 \mathrm{~d}$ of the 6 weeks of ad libitum access to regular chow was $24.8 \pm 0.6$ gm (PVN-EGFP control), $24.6 \pm 0.8$ gm (missed PVN-Agouti), and $29.0 \pm 0.7$ gm (PVNAgouti)]. Despite dense levels of MC4-R expression, we show that Agouti expression in the LH, in contrast to that in the PVN, did not affect body weight and food intake when animals were maintained on regular chow (Fig. 2C,D).

Unlike the rapid onset of obesity in PVN animals, onset was delayed when Agouti was expressed in the DMH. In the first 3 weeks after the injection, DMH-injected animals had similar levels of food intake and body weight when compared with controls. Thereafter, however, DMH-injected animals increased food intake and ate on average $2.5 \mathrm{gm} / \mathrm{d}$ more than controls. This resulted in a 30\% increase in body weight gain $(p=0.0001)$ (Fig. $2 E, F)$. Because the $\mathrm{DMH}$ is located only $0.76 \mathrm{~mm}$ posterior from the PVN region involved in acute onset obesity, we investigated whether the delayed onset in DMH animals was a consequence of Agouti leakage to the PVN region. To exclude this possibility, we showed that rAAV-Agouti did not increase food intake and body weight when injected $0.76 \mathrm{~mm}$ anterior, instead of posterior, to the PVN region. To also exclude the possibility that the delayed and Watson (1998)

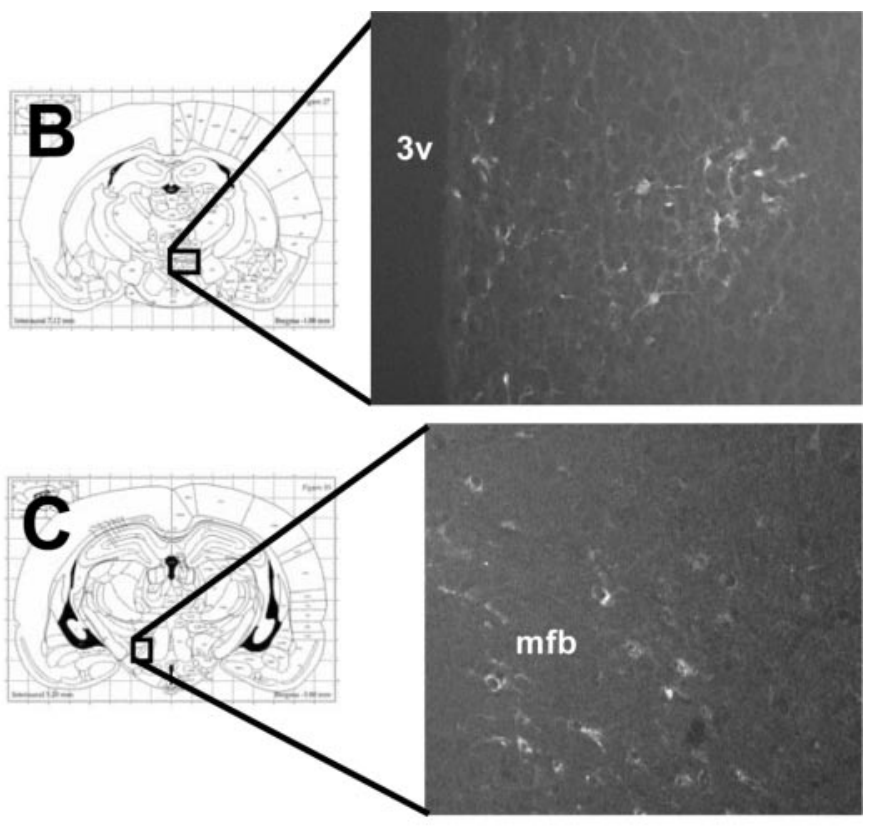

Figure 1. Agouti expression and secretion after infection with the rAAV-Agouti vector. Western blots $(A)$ of media from HEK

onset of increased food intake and body weight resulted from a later start time of expression of AAV constructs in the DMH when compared with the PVN, we confirmed that Agouti was expressed in the DMH as early as $3 \mathrm{~d}$ after the injection.

High-fat food is known to contribute to the development of obesity. Because Agouti expression in the LH did not contribute to food intake and body weight during regular chow, all animals were maintained on a high-energy diet with a high-fat content for 10 consecutive days to test diet responsiveness. This high-fat diet resulted in increased body weight gain in LH-Agouti animals when compared with LH-EGFP controls (Fig. 3A). Usually, this diet results in a suppression of daily food intake because of the higher caloric density of food (Adolph, 1947). However, animals with Agouti expression in the LH had a far less pronounced suppression of food intake when they were switched to a high-fat diet when compared with LH-EGFP control, DMH, and PVN-Agouti injected animals. Indeed, actual comparison of caloric intake during regular and high-fat diet in LH-Agouti and LH-EGFP control animals revealed that LH-Agouti animals had an increased caloric intake during the high-fat diet (Fig. $3 B$ ).

Local long-term Agouti expression in the PVN, DMH, and LH differentially induced hyperphagia and accelerated body weight gain without apparent changes in central neuropeptide systems that are known to stimulate food intake. We found that both AgRP and NPY mRNA levels in arcuate nucleus neurons, as well as $\mathrm{MCH}$ and orexin mRNA expression in the lateral hypothalamus, were not affected after long-term Agouti expression in the PVN, DMH, or LH (Fig. 4).

\section{Discussion}

Our results show that Agouti expression in the PVN induced a rapid onset of hyperphagia and body weight gain. This was not unexpected, because a single local injection of a MC agonist stimulates food intake (Kim et al., 2000; Wirth et al., 2001). Surpris- 

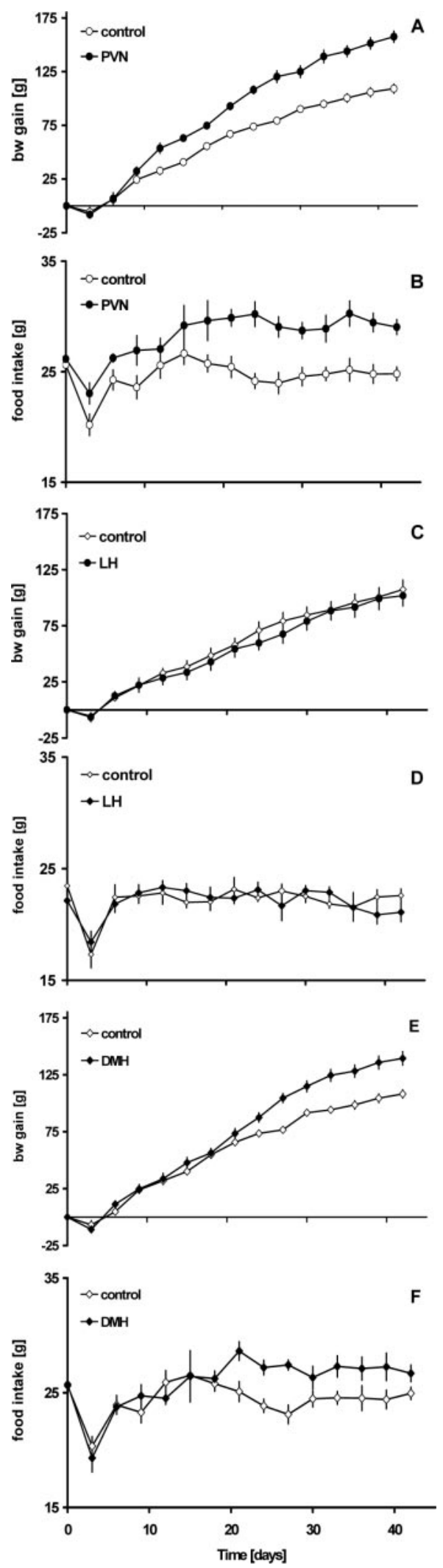

Figure 2. Agouti expression in the PVN and DMH results in acute and delayed onset longterm hyperphagia-induced obesity, respectively. Body weight (bw) gain $(A)$ and food intake (B) (both averaged over $3 \mathrm{~d}$ segments) are increased in animals with Agouti expression in the PVN when compared with EGFP control PVN-injected animals. During ad libitum access to regular chow, body weight gain and food intake were similar in animals with Agouti expression in the LH and EGFP control LH-injected animals $(C, D)$. In animals with Agouti expression in the DMH, the onset of increased body weight gain $(E)$ and food intake $(F)$ was delayed by 3 weeks,
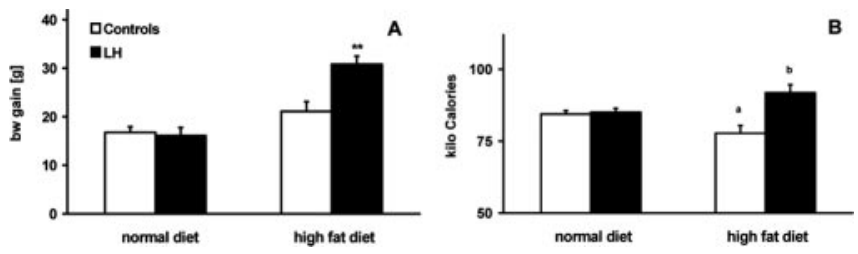

Figure 3. Agouti expression in the LH induced diet-induced obesity. Whereas LH-EGFP control and LH-Agouti injected animals had similar levels of body weight (bw) gain during a normal diet (body weight gain during the last $10 \mathrm{~d}$ of the normal diet), body weight gain significantly increased in animals with Agouti expression in the LH during $10 \mathrm{~d}$ of access to a high-fat diet (compared with body weight on the day before the high-fat diet) $(A)$. This increased body weight gain in LH-Agouti injected animals related to increased caloric intake in LH-Agouti animals during the high-fat diet $(B) .{ }^{* *} p<0.0001$, different from all other conditions; ${ }^{a} p=$ 0.006 , different from LH-EGFP during normal diet; ${ }^{b} p=0.003$, different from LH-EGFP during high-fat diet.

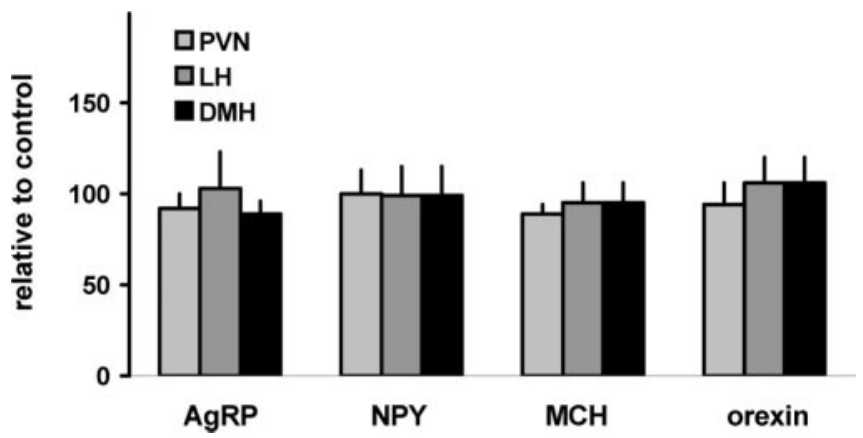

Figure 4. Hypothalamic mRNA expression levels of the orexigenic neuropeptides AgRP and NPY in the arcuate nucleus, as well as MCH and orexins in the lateral hypothalamus. After long-term local expression of Agouti in the PVN, DMH, and LH, no difference in mRNA expression levels were observed when compared with EGFP controls (in brains of rats from Figs. 2, 3). mRNA expression levels are expressed as a percentage from the EGFP controls. Because region-specific EGFP controls were not different in gene expression levels, their expression levels were pooled for the analysis.

ingly, Agouti expression in the DMH caused delayed onset of increased food intake and body weight, whereas LH-Agouti expression did not affect body weight on a regular diet but resulted in diet-induced obesity. Therefore, these data show that MC signaling in different brain regions contributes to different characteristics of the obesity syndrome and that the development of these characteristics, such as hyperphagia and diet-induced obesity, are under distinct neuroanatomical control in the brain. These findings open opportunities for additional research aimed at how these different brain regions control different aspects of energy homeostasis. Furthermore, the approach taken is readily available to investigate whether disruption of $\mathrm{MC}$ signaling in other brain regions implicated in regulation of food intake, such as the dorsal motor nucleus of the vagus nerve, also induce characteristics of the obesity syndrome.

Here we show that Agouti expression in the PVN and DMH both stimulates food intake and body weight; however, the tim-

$\leftarrow$

in contrast to the acute obesity onset in animals with Agouti expression in the PVN. In the first $3 \mathrm{~d}$ after surgery (days $0-3$ ), a decline in body weight gain and food intake was observed in all animals. Histological verification of Agouti expression was checked for all animals by means of Agouti immunoreactivity. Animals with Agouti-positive cells in the targeted regions (PVN, -1.80 to $-2.12 \mathrm{~mm}$ from bregma; $\mathrm{LH},-2.56$ to $-3.80 \mathrm{~mm}$ from bregma; $\mathrm{DMH},-2.56$ to $-3.14 \mathrm{~mm}$ from bregma) [region as defined using the atlas by Paxinos and Watson (1998)] were used for the analysis and resulted in the shown behavioral data set for these confirmed groups ( $n=6-7$ per group). 
ing of hyperphagia onset is significantly delayed in the DMH when compared with the PVN. Because these regions are closely located to each other, the DMH effects of Agouti may be explained by leakage of Agouti from the DMH to the PVN, resulting in a delayed onset of the PVN-induced hyperphagia. However, an acute or a delayed onset of hyperphagia and body weight increase were not found in animals with Agouti expression just outside the PVN (missed PVN injections) or $0.76 \mathrm{~mm}$ anterior to PVN (the $\mathrm{DMH}$ is located $0.76 \mathrm{~mm}$ posterior to $\mathrm{PVN}$ ). Therefore, these data make it unlikely that the delayed onset of hyperphagia after DMH-Agouti expression was caused by leakage of Agouti from the DMH to the PVN and indicate that disruption of MC signaling in the DMH does not result in immediate increased food intake and body weight, such as observed after AAV-Agouti injection in the PVN. Additional studies can now focus on the mechanisms underlying this late onset obesity and the role of the DMH therein.

The present data show that inhibition of MC signaling in the LH selectively accelerates the development of obesity on a highfat diet by affecting caloric intake. LH-Agouti injected animals had similar caloric intake and body weight gain on regular chow. However, Agouti expression in the LH resulted in an increased caloric intake and subsequent body weight gain on a high-fat diet when compared with LH-EGFP controls. Therefore, our data provide evidence that the $\mathrm{LH}$ is an important brain region for the protection against diet-induced obesity rather than for the induction of hyperphagia (as shown in the PVN). The increased caloric intake after inhibition of MC signaling in the LH may result from impaired satiety signaling during intake of high-fat food. In addition, recent studies suggest that the $\mathrm{LH}$ region integrates information about energy status and reward (Fulton et al., 2000). Additional behavioral and anatomical studies are needed to demonstrate how energy intake, energy expenditure, and possible reward mechanisms are integrated in the $\mathrm{LH}$.

To further characterize the different mechanisms underlying the brain region-specific forms of Agouti-induced obesity, mRNA gene expression levels of known orexigenic neuropeptides (NPY, AgRP, MCH, and orexins) were measured in several brain regions. Although local and long-term Agouti expression in the PVN, DMH, or LH had marked and different effects on body weight and food intake, no obvious changes in mRNA expression levels of these known orexigenic neuropeptide systems were observed. One interpretation of these results is that brain regionspecific disruption of MC-R signaling by Agouti leading to hyperphagia and accelerated weight gain on a high-fat diet is independent of regulation of the hypothalamic orexigenic neuropeptides NPY, AgRP, MCH, and orexins. This idea is consistent with previous data showing that blockade of MC-R signaling, although causing hyperphagia and obesity, did not lead to alterations in expression levels of a number of hypothalamic neuropeptides including, for example, NPY expression in the arcuate nucleus (Kesterson et al., 1997; Adage et al., 2001). We cannot rule out, however, that induction of Agouti expression did transiently alter expression of, at least, some of these neuropeptide systems, allowing these animals to become obese. Therefore, a more extensive analysis of time-dependent changes in these neuropeptide systems and other metabolic parameters may be required to further study physiological changes related to the observed brain region-specific forms of obesity induced by Agouti.

Together, these findings suggest that a single neuropeptide system, such as the MC system, regulates different adaptive behavioral and physiological strategies to alter an organism's energy balance toward a certain direction (e.g., energy conservation) in distinct brain nuclei. The brain homolog for Agouti, AgRP, is expressed in the arcuate nucleus of the hypothalamus and innervates a wide variety of brain regions, such as the PVN, DMH, and $\mathrm{LH}$. These arcuate nucleus neurons respond to sudden changes in peripheral molecules, such as leptin, glucose, and insulin, that provide information about the energy status of an organism. Starvation, for example, leads to a drop in leptin levels (Ahima et al., 1996) and subsequent increase in AgRP gene expression (Hahn et al., 1998). This will result in a simultaneous activation of distinct brain regions that, as indicated by the present study, regulate brain region-specific aspects of physiological processes, each contributing separately to energy conservation.

\section{References}

Adage T, Scheurink AJ, de Boer SF, de Vries K, Konsman JP, Kuipers F, Adan RA, Baskin DG, Schwartz MW, van Dijk G (2001) Hypothalamic, metabolic, and behavioral responses to pharmacological inhibition of CNS melanocortin signaling in rats. J Neurosci 21:3639-3645.

Adolph EF (1947) Urges to eat and drink in rats. Am J Physiol 151:110-125. Ahima RS, Prabakaran D, Mantzoros C, Qu D, Lowell B, Maratos-Flier E, Flier JS (1996) Role of leptin in the neuroendocrine response to fasting. Nature 382:250-252.

Anand BK, Brobeck JR (1951) Localization of a "feeding center" in the hypothalamus of the rat. Proc Soc Exp Biol Med 77:323-324.

Butler AA, Marks DL, Fan W, Kuhn CM, Bartolome M, Cone RD (2001) Melanocortin-4 receptor is required for acute homeostatic responses to increased dietary fat. Nat Neurosci 4:605-611.

Chen P, Williams SM, Grove KL, Smith MS (2004) Melanocortin 4 receptor-mediated hyperphagia and activation of neuropeptide $\mathrm{Y}$ expression in the dorsomedial hypothalamus during lactation. J Neurosci 24:5091-5100.

Chen W, Shields TS, Stork PJ, Cone RD (1995) A colorimetric assay for measuring activation of Gs- and Gq-coupled signaling pathways. Anal Biochem 226:349-354.

de Lecea L, Kilduff TS, Peyron C, Gao X, Foye PE, Danielson PE, Fukuhara C, Battenberg EL, Gautvik VT, Bartlett FS, Frankel WN, van den Pol AN, Bloom FE, Gautvik KM, Sutcliffe JG (1998) The hypocretins: hypothalamus-specific peptides with neuroexcitatory activity. Proc Natl Acad Sci USA 95:322-327.

Delgado J, Anand BK (1953) Increase of food intake induced by electrical stimulation of the lateral hypothalamus. J Comp Physiol 172:162-168.

Duhl DM, Stevens ME, Vrieling H, Saxon PJ, Miller MW, Epstein CJ, Barsh GS (1994) Pleiotropic effects of the mouse lethal yellow (Ay) mutation explained by deletion of a maternally expressed gene and the simultaneous production of agouti fusion RNAs. Development 120:1695-1708.

Eaton MJ, Blits B, Ruitenberg MJ, Verhaagen J, Oudega M (2002) Amelioration of chronic neuropathic pain after partial nerve injury by adenoassociated viral (AAV) vector-mediated over-expression of BDNF in the rat spinal cord. Gene Ther 9:1387-1395.

Fan W, Boston BA, Kesterson RA, Hruby VJ, Cone RD (1997) Role of melanocortinergic neurons in feeding and the agouti obesity syndrome. Nature 385:165-168.

Fulton S, Woodside B, Shizgal P (2000) Modulation of brain reward circuitry by leptin. Science 287:125-128.

Gantz I, Miwa H, Konda Y, Shimoto Y, Tashiro T, Watson SJ, DelValle J, Yamada T (1993) Molecular cloning, expression, and gene localization of a fourth melanocortin receptor. J Biol Chem 268:15174-15179.

Grimm D, Kern A, Rittner K, Kleinschmidt JA (1998) Novel tools for production and purification of recombinant adenoassociated virus vectors. Hum Gene Ther 9:2745-2760.

Hahn TM, Breininger JF, Baskin DG, Schwartz MW (1998) Coexpression of Agrp and NPY in fasting-activated hypothalamic neurons. Nat Neurosci $1: 271-272$

Hermens WT, ter Brake O, Dijkhuizen PA, Sonnemans MA, Grimm D, Kleinschmidt JA, Verhaagen J (1999) Purification of recombinant adenoassociated virus by iodixanol gradient ultracentrifugation allows rapid and reproducible preparation of vector stocks for gene transfer in the nervous system. Hum Gene Ther 10:1885-1891.

Huszar D, Lynch CA, Fairchild-Huntress V, Dunmore JH, Fang Q, Berkemeier LR, Gu W, Kesterson RA, Boston BA, Cone RD, Smith FJ, Camp- 
field LA, Burn P, Lee F (1997) Targeted disruption of the melanocortin-4 receptor results in obesity in mice. Cell 88:131-141.

Katafuchi T, Oomura Y, Yoshimatsu H (1985) Single neuron activity in the rat lateral hypothalamus during 2-deoxy-D-glucose induced and natural feeding behavior. Brain Res 359:1-9.

Kesterson RA, Huszar D, Lynch CA, Simerly RB, Cone RD (1997) Induction of neuropeptide $\mathrm{Y}$ gene expression in the dorsal medial hypothalamic nucleus in two models of the agouti obesity syndrome. Mol Endocrinol 11:630-637.

Kim MS, Rossi M, Abusnana S, Sunter D, Morgan DG, Small CJ, Edwards CM, Heath MM, Stanley SA, Seal LJ, Bhatti JR, Smith DM, Ghatei MA, Bloom SR (2000) Hypothalamic localization of the feeding effect of agouti-related peptide and alpha-melanocyte-stimulating hormone. Diabetes 49:177-182.

Kishi T, Aschkenasi CJ, Lee CE, Mountjoy KG, Saper CB, Elmquist JK (2003) Expression of melanocortin 4 receptor mRNA in the central nervous system of the rat. J Comp Neurol 457:213-235.

Lu D, Willard D, Patel IR, Kadwell S, Overton L, Kost T, Luther M, Chen W, Woychik RP, Wilkison WO (1994) Agouti protein is an antagonist of the melanocyte-stimulating-hormone receptor. Nature 371:799-802.

Mountjoy KG, Mortrud MT, Low MJ, Simerly RB, Cone RD (1994) Localization of the melanocortin-4 receptor (MC4-R) in neuroendocrine and autonomic control circuits in the brain. Mol Endocrinol 8:1298-1308.

Ollmann MM, Lamoreux ML, Wilson BD, Barsh GS (1998) Interaction of
Agouti protein with the melanocortin 1 receptor in vitro and in vivo. Genes Dev 12:316-330.

Oosterom J, Nijenhuis WA, Schaaper WM, Slootstra J, Meloen RH, Gispen WH, Burbach JP, Adan RA (1999) Conformation of the core sequence in melanocortin peptides directs selectivity for the melanocortin MC3 and MC4 receptors. J Biol Chem 274:16853-16860.

Paxinos G, Watson C (1998) The rat brain in stereotaxic coordinates, Ed 4. New York: Academic.

Sakurai T, Amemiya A, Ishii M, Matsuzaki I, Chemelli RM, Tanaka H, Williams SC, Richardson JA, Kozlowski GP, Wilson S, Arch JR, Buckingham RE, Haynes AC, Carr SA, Annan RS, McNulty DE, Liu WS, Terrett JA, Elshourbagy NA, Bergsma DJ, Yanagisawa M (1998) Orexins and orexin receptors: a family of hypothalamic neuropeptides and G proteincoupled receptors that regulate feeding behavior. Cell 92:573-585.

van der Kraan M, Adan RA, Entwistle ML, Gispen WH, Burbach JP, Tatro JB (1998) Expression of melanocortin-5 receptor in secretory epithelia supports a functional role in exocrine and endocrine glands. Endocrinology 139:2348-2355.

Wirth MM, Olszewski PK, Yu C, Levine AS, Giraudo SQ (2001) Paraventricular hypothalamic alpha-melanocyte-stimulating hormone and MTII reduce feeding without causing aversive effects. Peptides 22:129-134.

Zamir N, Skofitsch G, Bannon MJ, Jacobowitz DM (1986) Melaninconcentrating hormone: unique peptide neuronal system in the rat brain and pituitary gland. Proc Natl Acad Sci USA 83:1528-1531. 